NBER WORKING PAPER SERIES

\title{
DOES EMPLOYER-PROVIDED HEALTH INSURANCE CONSTRAIN LABOR SUPPLY ADJUSTMENTS TO HEALTH SHOCKS? NEW EVIDENCE ON WOMEN DIAGNOSED WITH BREAST CANCER
}

\author{
Cathy J. Bradley \\ David Neumark \\ Scott Barkowski \\ Working Paper 18060 \\ http://www.nber.org/papers/w18060
NATIONAL BUREAU OF ECONOMIC RESEARCH
1050 Massachusetts Avenue
Cambridge, MA 02138
May 2012

Bradley, Neumark, and Barkowski's research was supported by NCI grant number R01-CA122145, "Health, Health Insurance, and Labor Supply." The authors are grateful to Myra Owens, Ph.D. and Mirna Hernandez for project coordination, Meryl Motika for programming support, the interviewers and medical record auditors that collected the data, and the many subjects who generously donated their time to the project. The views expressed herein are those of the authors and do not necessarily reflect the views of the National Bureau of Economic Research.

NBER working papers are circulated for discussion and comment purposes. They have not been peerreviewed or been subject to the review by the NBER Board of Directors that accompanies official NBER publications.

(C) 2012 by Cathy J. Bradley, David Neumark, and Scott Barkowski. All rights reserved. Short sections of text, not to exceed two paragraphs, may be quoted without explicit permission provided that full credit, including $(\mathbb{C}$ notice, is given to the source. 
Does Employer-Provided Health Insurance Constrain Labor Supply Adjustments to Health Shocks? New Evidence on Women Diagnosed with Breast Cancer

Cathy J. Bradley, David Neumark, and Scott Barkowski

NBER Working Paper No. 18060

May 2012

JEL No. I13,J2

\begin{abstract}
$\underline{\text { ABSTRACT }}$
Employment-contingent health insurance creates incentives for ill workers to remain employed at a sufficient level (usually full-time) to maintain access to health insurance coverage. We study employed married women, newly diagnosed with breast cancer, comparing labor supply responses to breast cancer diagnoses between women dependent on their own employment for health insurance and women with access to health insurance through their spouse's employer. We find evidence that women more dependent on their own job for health insurance reduce their labor supply by less after a diagnosis of breast cancer - the estimate difference is about 5.5 to 7 percent. Women's subjective responses to questions about working more to maintain health insurance are consistent with the conclusions from observed behavior.

Cathy J. Bradley

Department of Healthcare Policy and Research Virginia Commonwealth University 830 E. Main Street

Richmond, VA 23219

cjbradley@vcu.edu

David Neumark

Department of Economics

University of California at Irvine

3151 Social Science Plaza

Irvine, CA 92697

and NBER

dneumark@uci.edu

Scott Barkowski

Department of Economics

University of California at Irvine

3151 Social Science Plaza

Irvine, CA 92697

scott.barkowski@uci.edu
\end{abstract}




\section{Introduction}

Provision of health insurance through an employer complicates workers' decisions when they are faced with serious health conditions that require expensive treatment and long periods of recovery. Although workers may want to invest in their health by taking time away from work for treatment and recovery, their demand for health insurance rises with increased risk of health care expenses. Employer-provided health insurance is often only offered to or taken up by fulltime employees, in which case ill workers must not only remain employed, but must work enough hours to be considered full-time to qualify for health insurance benefits. As a consequence, the opportunity cost of forgoing work for treatment (or recovery) could be considerable since it could lead to loss of insurance coverage (or an increased cost of coverage if health insurance is available for part-time workers at a greater cost to the worker). This is potentially important because there may be adverse health consequences of remaining employed at a level sufficient to keep health insurance; work could conflict with recovery, or it could influence treatment decisions or adherence with a treatment plan.

For an ill employee, losing access to insurance through one's employer leaves few options to obtain health insurance. One possibility is continuing coverage through the Consolidated Omnibus Budget Reconciliation Act (COBRA) of 1985. However, former employees pay the full cost of group coverage, and the policy is usually limited to 18 to 36 months - making continuation of coverage via COBRA a prohibitively expensive option for many and only a temporary measure even for those who can afford it. ${ }^{1}$

The Health Insurance Portability and Accountability Act (HIPAA) of 1996 allows employees to add to their insurance policy a spouse or other dependents who lose job-related

\footnotetext{
${ }^{1}$ The American Recovery and Reinvestment Act (ARRA) of 2009 provided a premium reduction (to $35 \%$ of premiums) for continuation coverage for eligible individuals who were terminated involuntarily from employment through May 31, 2010. Individuals who qualified paid reduced premiums for up to 15 months, as long as they were not eligible for another group health plan or Medicare (U.S. Department of Labor, 2011).
} 
coverage, which is another avenue by which a worker who becomes ill may secure health insurance coverage without remaining employed. However, HIPAA offers no protection to many ill workers, including those who are unmarried, those whose spouses are not employed, and those with employed spouses whose employer does not offer health insurance coverage for family members.

Lastly, the Patient Protection and Affordable Care Act (ACA), passed in 2010, would expand Medicaid coverage to very low-income workers who lose employer-provided coverage and allow others without employer-provided coverage to purchase health insurance on exchange markets. ${ }^{2}$ Nonetheless, ACA policy discussions mainly focus on the provision of health insurance to the uninsured, leaving the employer-provided system largely intact.

In prior research, Bradley et al. (2006) developed a theoretical framework showing that when insurance is contingent on continued employment, an employee may forgo health care or convalescence that requires extended time away from work and instead devote time towards work to preserve health insurance coverage. The theoretical framework supports the paradox that although health shocks with the greatest financial impacts may entail the greatest morbidity, the incentive to maintain health insurance (which often requires keeping hours worked high to retain insurance or prevent its cost from rising sharply) may counter the need for time away from work. This tension between work and recovery potentially creates difficult choices for ill workers, and those induced to choose more work rather than more time to recover may suffer worse health outcomes. ${ }^{3}$

\footnotetext{
${ }^{2}$ The ACA would extend Medicaid to uninsured individuals below $138 \%$ of the Federal Poverty Line (Kaiser Family Foundation, 2011).

${ }^{3}$ The Family Medical Leave Act (FMLA) entitles eligible employees of covered employers to take unpaid, jobprotected leave for specified family and medical reasons with continuation of group health insurance coverage (U.S. Department of Labor, 2012). However, not all workers are covered by FMLA, some workers may fear that using FMLA will result in adverse consequences at work, and some workers may remain at their jobs or remain full-time employees to ensure that they retain health insurance. Nonetheless, FMLA seems likely to mute the extent to which people with health shocks are constrained to remain at work and not reduce their hours.
} 
This paper studies labor supply changes following health shocks, comparing married women newly diagnosed with breast cancer and dependent on their own job for health insurance to similar women who are insured through a spouse's policy or with access to such insurance. We survey women within a few months following a breast cancer diagnosis and within two months of initiating treatment about their labor supply and job characteristics prior to diagnosis. We then survey them again about nine months after treatment. The surveys cover three distinct periods: prior to diagnosis (retrospectively), two months after initiation of treatment, and nine months after initiation of treatment. By focusing on the time period immediately following treatment initiation, we observe labor supply behavior when treatment demands are greatest and decisions have to be made about maintaining hours of employment or even remaining employed at all. We include a core set of analyses that replicate Bradley et al. (2006), but we use a sample specifically constructed to address the relationship between labor supply and dependence on one's job for health insurance in a breast cancer context.

We also present new analyses exploring in more detail responses of women who depend on their jobs for health insurance, constructing comparisons with subsets of women who are less dependent on their own employment for health insurance, but who are more likely to be similar in terms of unobservables such as job characteristics and commitment to work, for which we cannot fully control. For example, one comparison focuses only on those women offered health insurance through their employer (which we term ECHI, for "employment-contingent health insurance"), and distinguishes between those who enrolled and those who declined and instead took insurance through their spouse's employer. Women offered ECHI may have similar jobs, whereas a comparison between women with and without ECHI may be driven largely by the differences between women offered and not offered ECHI, whose jobs likely differ on other dimensions. Thus, among those offered ECHI, the difference between those who do and do not 
enroll more cleanly reflects the difference in how dependent one is on their own job for insurance. A second comparison is again only among the more homogeneous group of women with ECHI, but contrasting those who have the option to switch to a spouse's policy with those who do not.

\section{Labor Market Incentives from Employer-Based Health Insurance}

The studies most relevant to our investigation directly examine labor supply following a health shock, although only a handful of studies fit this description, suggesting a substantial gap in the literature that can be addressed by the current study. There are also studies of "job lock" a phenomenon conjectured to occur when workers remain in their current job to retain health insurance. These studies are related because they link the need for health insurance to being "locked" into a job - i.e., employees with health conditions (or whose family members have health conditions), who have employer-provided health insurance, should be more reluctant to leave their jobs than healthy employees (who also have healthy families) because other jobs may not offer health insurance or, if they do, may be less secure than their current job. Although there is a larger literature on job lock, we focus our discussion on studies that incorporate health status of the employee (or their dependents) into their analysis.

Labor supply and health conditions. We are aware of three studies of labor supply that report evidence on how workers with employer-provided health insurance respond to illness. In a study using primary data collected from a sample of married Detroit women with breast cancer, those with ECHI were significantly more likely to remain employed relative to women whose insurance was provided by another source, and ECHI moderated the negative impact of cancer on weekly hours worked (Bradley et al., 2006). Specifically, women with ECHI were 10 percentage points more likely to remain employed six months following diagnosis than women with insurance through another source, rising to 17 percentage points at 18 months following 
diagnosis. Similarly, Tunceli et al. (2009), using data from cancer survivors two to six years following diagnosis, and a non-cancer sample drawn from the Health and Retirement Study (HRS), reported higher employment rates after a cancer diagnosis for those with ECHI as opposed to either another source of health insurance or being uninsured. The negative influences of ECHI on transitions to non-employment or part-time employment, or other job changes, were significant for both genders in the cancer sample, but strongest for men. Using the HRS to identify respondents with a broad range of health shocks, and a comparison group without health shocks, Bradley et al. (2011) found that for some specifications of health shocks ECHI encourages continued employment of men, although not of women. In particular, this was true for health shocks mainly associated with higher future costs of health care rather than current morbidity that could itself directly reduce employment.

Although the literature on how ECHI affects labor supply following a health shock is scant, it generally suggests that ECHI dampens the negative labor supply response to illness, as employees with ECHI appear to work at higher levels following illness, presumably to maintain insurance. One likely reason for the small quantity of research is that in national databases such as the HRS the prevalence of illness and/or poor health status is too low, especially among employed individuals, to provide adequate sample sizes for study. Furthermore, illnesses are heterogeneous in type, severity, and treatment, but few studies collect sufficient detail on illness and treatment to adequately control for these differences in analyses. Thus, researchers seeking to study this topic are limited by the secondary data sources available. This motivates efforts to collect primary data from a sample of individuals with a similar disease followed by similar treatments.

Job lock. Cooper and Monheit's seminal work on job lock suggested that the phenomenon was important. Studying a sample of workers aged 25 to 55, they estimated that 
employer-provided health insurance reduced the likelihood a worker changed jobs by $25 \%$ among married males, the group with the strongest labor force attachment, up to $38 \%$ for married females, the group with the weakest attachment (Cooper and Monheit, 1993). Madrian (1994) compared the influence of employer-provided health insurance for samples that had high and low medical expenditures as defined by family size and the occurrence of a pregnancy. She found evidence that job lock reduced voluntary job changes for those with employer-provided health insurance by $25 \%$.

Other research, however, finds weaker effects. Kapur (1998) improved the research on job lock by using several measures of health status including medical conditions, nights in a hospital, emergency department visits, medical visits, prescribed medications, and medical expenses. She found little evidence of job lock. Gilleskie and Lutz (2002), using broader measures of health status (e.g., health limitation, disability, age, body mass index, and crack use), found only a modest effect (10\% to 15\%, or about one-half of Cooper and Monheit's (1993) estimates). Still, these studies are problematic because health conditions are heterogeneous in type, severity, and future expected health care expenses. Illnesses with high future expected expenses, for example, would be expected to exhibit a stronger negative relationship between employer-provided health insurance and job mobility, whereas conditions that are short-lived may have little influence on the relationship between health insurance and job mobility. Therefore, when there are heterogeneous health conditions it may be difficult to detect evidence of job lock. ${ }^{4}$

Aside from health conditions, job and worker characteristics could drive evidence that looks like job lock - and similarly could drive evidence indicating that ECHI dampens labor supply reductions when a worker experiences a health shock. Jobs that offer health insurance

\footnotetext{
${ }^{4}$ This same problem can arise in research on labor supply responses to health shocks depending on whether one has ECHI, and may help explain variation in results across different kinds of diagnoses in Bradley et al. (2011).
} 
also have other benefits including pensions, life insurance, sick leave, and paid vacations, and may also pay higher wages and offer better working conditions. All of these factors may reduce turnover because of other economic incentives (like maintaining pensions), or may dampen labor supply responses by making it easier for ill workers to continue working. Turnover and labor supply responses may also be more moderate if these jobs attract less mobile or more committed workers. To address this issue, Gilleskie and Lutz (2002) incorporated data regarding the offer of health insurance into a model of the relationship between unobserved individual characteristics that are correlated with the offer of health insurance, the acceptance of insurance, and employment transitions, and argue that their results provide an estimate of job lock that is not biased from correlations between the provision of health insurance and job characteristics. They found no evidence of job lock for married men and only a modest effect for unmarried men. In the current paper, we also pay close attention to unobserved individual and job characteristics correlated with ECHI that can influence labor supply responses to a health shock.

\section{Application to Breast Cancer}

Female breast cancer survivors comprise the largest percentage of all cancer survivors, approximately $23 \%$, and the largest percentage (41\%) of all female cancer survivors (National Cancer Institute, 2011a). Five-year survival rates exceed $83 \%$ for women diagnosed with regional stage disease and $96 \%$ for women with local stage disease (National Cancer Institute, 2011b). There are numerous studies of breast cancer's impact on employment, motivated by the fact that with screening and earlier detection, working age women are more likely to be diagnosed with and treated for the disease. One study found that women with breast cancer were 17 percentage points less likely to be employed than women in a non-cancer control group six months following diagnosis, but by 12 and 18 months following diagnosis, their likelihood of employment was not statistically different (Bradley et al., 2007). Recent studies of breast cancer 
and employment also find evidence that breast cancer does not lead to substantial longer-term declines in employment; examining over 1,000 initially-employed women diagnosed with breast cancer, Mujahid et al. (2011) report that approximately 90\% were employed nine months following diagnosis, although non-employment rates were higher for Latina women than for white women.

Although the evidence points to high long-term rates of return to work on average, women with more extensive disease that requires several months of chemotherapy and/or radiation may experience greater work interruption than women treated with surgery alone (Stephan, 2010). In addition to the time away from work required for treatment, women who receive chemotherapy experience considerable morbidity, which can negatively affect their ability to return to work. For example, Hassett et al. (2009) reported return to work rates of $93 \%$ among over 3,200 employed and insured women, but those who received chemotherapy were more likely to go on disability, stop working, or retire relative to women who did not receive chemotherapy. The effects of chemotherapy can continue for several months or even years following the completion of treatment (Bradley et al., 2007; Johnsson et al., 2011; Hassett et al., 2009).

In spite of the morbidities imposed by breast cancer treatments, women have a strong incentive to continue working if they are dependent on their jobs for health insurance. The cost of breast cancer treatment for insured women in 2007 was estimated to be $\$ 66,489$, and out-ofpocket expenses for women with employer-provided coverage were estimated to be $\$ 6,250$ (Gabel et al., 2009). Given high survival rates, once women are successfully treated for the disease, their worries may turn from survival to the future costs of care for cancer surveillance, second primary cancers, and reoccurrence of the first primary cancer.

Capitalizing on our knowledge of breast cancer's impact on employment, and our past 
experience recruiting, enrolling, and studying breast cancer patients, we designed a study to address the intersection of breast cancer, employment, and employment-provided health insurance. The earlier research on employment and hours responses (Bradley et al., 2006) used a sample limited to a single metropolitan area (Detroit, MI) and collected limited information on cancer treatment. Our current study of ECHI and breast cancer was designed to overcome these limitations. Most importantly, it targeted women who received chemotherapy or radiation (or both), since non-employment effects and incentives to remain employed are likely to be strongest among them; these treatments are the most costly and are more likely to entail both severe disease (making the chances of reoccurrence higher) and long-term side effects from the chemotherapy or radiation. In addition to these reasons, we study women with breast cancer because we can determine disease severity and the uniformity of treatment by disease stage. These conditions allow us to isolate ECHI's incentives without introducing noise due to differences in diseases and treatments. These new data provide a more complete picture of how employer-provided health insurance affects labor supply responses to illness than has been available to date.

\section{Data}

We conducted a study using a quasi-experimental design to examine how of dependence on one's job for health insurance influences the labor supply responses of women newly diagnosed with breast cancer. We enrolled 496 employed, married women within two months following surgery or initiation of chemotherapy or radiation. The women had to have ECHI, or be covered by their spouse's employer-provided health insurance. We refer to the latter as "nonECHI." ${ }^{, 5}$ We aimed to enroll women with chemotherapy and/or radiation, although a small number of women in our sample did not pursue these options and others were recommended

\footnotetext{
${ }^{5}$ The non-ECHI group includes a handful of women covered by their spouse's military insurance (5 of the 195 women in the final sample who coded as non-ECHI).
} 
against chemotherapy and/or radiation following results from surgery. ${ }^{6}$ The study was powered to detect statistically significant differences $(\mathrm{p}<.05)$ in the proportion subsequently employed between those with and without ECHI, based on estimated effect sizes from prior work. In that prior work, $85 \%$ of women with ECHI and $70 \%$ of women without ECHI remained employed following diagnosis and treatment (Bradley et al., 2006). To detect this effect size, we required a minimum of 134 women in each group, but ultimately aimed to enroll 500 women with 250 in each group, anticipating that we would retain 220 in each group throughout the study. ${ }^{7}$ Enrolling women with health insurance through their spouse proved to be more difficult than anticipated because a greater share of eligible women was covered through their own employer than we observed in the past (Bradley et al., 2006). As a result, when enrollment ended, we had 278 subjects with ECHI and 218 with insurance through their spouse's employer-provided policy.

To obtain this sample, we collaborated with three hospital-based treatment centers and five private oncology centers from urban and rural areas in Virginia. Figure 1 traces out how we got from our initial subjects identified to our analysis sample. We reviewed the records of 5,840 breast cancer patients to identify prospective study subjects. Inclusion criteria were: married, between ages 21 and 64 years at the time of diagnosis, employed at diagnosis, and insured either through their own employer or through a spouse's employer. ${ }^{8}$ Subjects had to be without metastatic disease ${ }^{9}$ and within two months of initiating chemotherapy and/or radiation or for the few cases of women who did not receive these treatments, within two months following surgery. Letters were mailed to eligible subjects' physicians ( $\mathrm{N}=749)$. Physicians of three subjects refused to allow us to contact their patients. We mailed letters and consent forms to 746 women.

\footnotetext{
${ }^{6}$ There were 28 women in the sample who did not receive chemotherapy or radiation.

${ }^{7}$ This sample size was larger than what we needed to detect the effect size for changes in hours of work based on the prior evidence.

${ }^{8}$ The factor most responsible for exclusion from the sample was age greater than or equal to 65 .

${ }^{9}$ Treatment for metastatic disease is generally palliative without clear rules for when to stop chemotherapy.
} 
Interviewers then telephoned the women to screen for eligibility. Only $124(20 \%)$ of eligible women refused to participate; $82(11.1 \%)$ were ineligible for the study because they had multiple insurance sources or were uninsured; and we were unable to contact $44(6 \%)$ women. If we include subjects who we were unable to contact in the refusal rate (possibly passive refusals), the refusal rises slightly (25.3\%). Women who refused were approximately two years older than retained subjects, and more likely to be white.

We retained $92 \%$ of the sample over the nine-month study period. Women who dropped out of the study were comparable to women retained in terms of age and insurance source, but were more likely to be white. Among those who dropped out of the study and for whom we have cancer stage information, fewer had ductal carcinoma in situ relative to those who completed the study ( $8 \%$ versus $16 \%$ ), and more of the drop-outs had stage III cancer $(20 \%)$ than the retained sample (9\%). The difference in stage between those retained and those who dropped out may lead to more muted labor supply reductions. Abbreviated surveys were completed by 18 of the dropouts (47.4\%), of which 10 had ECHI and 8 had insurance through their spouse. Only one of these women reported that they were no longer working. Given the small number of drop-outs overall, we suspect the impact on the analysis is minimal. Lastly, two women died before completing all interviews and were removed from the sample. Starting in the fall of 2007, we interviewed women covering three periods: at enrollment (a retrospective interview that referred to the employment situation at diagnosis), during chemotherapy or radiation treatment (approximately 2 months following the initiation of treatment - in many cases coupled with the same interview that collected the retrospective information), and approximately 9 months following treatment initiation. The majority of women ( $85 \%)$ completed treatment by the last interview.

The questionnaire asked about subject and spouse demographic characteristics, job 
characteristics, job involvement, job satisfaction, insurance characteristics, and mental and physical health status. In addition to the telephone interview, we conducted audits of subjects' medical records. These audits extracted detailed information about cancer stage, surgery, chemotherapy regimen, and radiation. All interviews were audio recorded; quality control checks of the audio recordings against data entry revealed a data entry error rate below $1 \% .{ }^{10}$ The last interview was completed in September 2011. ${ }^{11}$

\section{Empirical Approach}

The transition from employment to non-employment and the percentage change in weekly hours worked are modeled as functions of source of health insurance prior to diagnosis (either ECHI or spouse insurance in our baseline specification, with INS an indicator of having one form of insurance or the other), breast cancer stage (BCA) ${ }^{12}$ other exogenous variables (the vector of these other variables and BCA are denoted X), and unobserved influences ( $(\varepsilon)$. Breast cancer stage is categorized as ductal carcinoma in situ (DCIS or stage 0), Stage I (tumor $<2 \mathrm{~cm}$ and no lymph node involvement), Stage II (tumor $<2 \mathrm{~cm}$ and lymph node involvement or tumor $<5 \mathrm{~cm}$ without lymph node involvement), and Stage III (cancer present in the axillary lymph nodes and chest wall). Stage IV is metastatic cancer. Although we excluded patients with Stage IV disease from initial study enrollment, three such patients were included in the sample who were thought to have earlier stage disease but were later found to have distant metastases.

We estimate the employment equation for post-diagnosis periods using,

$$
\mathrm{E}_{i t}{ }^{*}=\alpha_{\mathrm{E}}+\beta_{\mathrm{E}} \mathrm{ECHI}_{i 1}+\mathrm{X}_{i 1} \gamma_{\mathrm{E}}+\varepsilon_{i t} \mid \mathrm{E}_{i 1}=1 \text { and } \mathrm{INS}_{i 1}=1 \text {. }
$$

\footnotetext{
${ }^{10}$ The error rate was defined as the number of incorrectly entered responses out of all questions. The total number of questions varied, depending on the skip patterns for a particular subject. We defined a "critical error rate" as the number of incorrect responses that invoked an incorrect skip pattern or affected study outcomes of employment or hours worked. The critical error rate was also less than $1 \%$.

${ }^{11}$ The questionnaire is available upon request.

${ }^{12}$ Breast cancer stage was determined using the American Joint Commission on Cancer staging criteria, which incorporates Tumor, Node, and Metastases. Cancer stage is used to decide treatment course and is the best indicator of prognosis.
} 
We define employment status as a binary variable $\left(E_{i t}\right)$ that equals one if a woman reports that she worked for pay one or more hours per week. We estimate separate linear probability models for employment at the two- and nine- month interviews. The subscript $i$ refers to the $i$ th individual and the subscript $t$ refers to the interview period ( $t=1$ for the baseline interview period, $t=2$ for the two-month interview, and $t=3$ for the nine-month interview), and $\alpha_{\mathrm{E}}, \beta_{\mathrm{E}}$, and $\gamma_{\mathrm{E}}$ are parameters.

In our estimation of the effect of ECHI on weekly hours worked $(\mathrm{H})$, we assume that the same variables that affect employment also potentially affect hours worked. We estimate percent change in hours worked relative to the onset of breast cancer.

$$
\left\{\mathrm{H}_{i t}-\mathrm{H}_{i 1}\right\} / \mathrm{H}_{i 1}=\alpha_{\mathrm{H}}+\beta_{\mathrm{H}} \mathrm{ECHI}_{i 1}+\mathrm{X}_{i 1} \gamma_{\mathrm{H}}+\varepsilon_{i t} \mid \mathrm{E}_{i t}=1 \text { and } \mathrm{INS}_{i 1}=1
$$

We also report results from similar models of the percent change in weekly hours worked that are not conditional on employment after diagnosis. These unconditional models also capture the effect of non-employment for women no longer working. Weekly hours worked postdiagnosis are zero for women who report that they are not employed. The conditional and unconditional hours equations are estimated separately for the two- and nine-month interviews, and all models are estimated using Ordinary Least Squares (OLS) and all reported standard errors are clustered at the physician level.

\section{Control variables}

The control variables describing the respondents and their job characteristics are measured for the pre-diagnosis period. We control for weekly hours worked at baseline, individual characteristics including age, race (Non-Hispanic white, Non-Hispanic African American, and other), education (high school diploma or less, some college or Associate's

degree, Bachelor's degree, advanced degree), whether the subject has children under age 18, occupation type (white collar or blue collar), and annual household income $(<\$ 40,000$, between 
$\$ 40,000$ and $\$ 74,999$, between $\$ 75,000$ and $\$ 150,000,>\$ 150,000)$. Age is specified as a continuous variable. All estimations include dummy variables for the year of the interview (2007-2011) as well as an indicator whether the patient ever received chemotherapy or radiation treatment at any point.

In addition to these patient-level controls, in expanded specifications we add controls that are more specific as to the timing and type of treatment (separate indicators for whether chemotherapy and/or radiation was being received at the time of the 2-month and/or 9-month interview), job characteristics, and share of household income that was contributed by the subject. Job characteristics (in addition to blue- and white-collar designations) include firm size ( $<25,25$ to 49,50 to 99,100 or more employees), employer type (government, private for-profit, non-profit, and self-employed), and job tasks.

Job task questions paralleled those in the HRS. These questions asked if the woman agreed with statements such as "My job involves a lot of physical effort." The response categories were all/almost all of the time, most of the time, some of the time, or none/almost none of the time, for the following tasks: physical effort, lifting heavy loads, stooping, kneeling, crouching, intense concentration/attention, data analysis, keeping up with the pace set by others, learning new things, and whether the job requires good eyesight. We dichotomized responses into all/almost all of the time and most of the time versus some of the time or none/almost none of the time. We also asked subjects to report the number of hours they spent sitting per day and created a dummy variable indicating if the respondent spent less than 2.5 hours, 2.5 to 5,5 to 7 , or more than 7 hours a day sitting. Share of household income contributed by the subject was categorized as $\leq 25 \%, 26 \%$ to $50 \%, 51 \%$ to $75 \%$, and $>75 \%$.

\section{Alternative Comparisons}

Our baseline analysis compares the labor response to health shocks for women with and 
without ECHI. However, there may be unobserved differences between women with ECHI and women without ECHI, and likewise there may be differences between jobs that offer ECHI and jobs that do not. Either these individual or job differences may affect the labor supply response to health shocks, leading to spurious attributions of response differences to dependence on employment for health insurance. For example, women with ECHI could be more persistent or committed workers less likely to reduce labor supply in response to a health shock, or, conversely, they could be in jobs that are more accommodating to health shocks allowing for greater labor supply reductions; in other words, biases from unobserved differences between women based on whether or not they have ECHI could in principle bias the estimates in either direction.

To address these concerns, we estimated three additional specifications intended to provide cleaner assessments of how women's dependency on their jobs for health insurance affects their labor supply responses to a breast cancer diagnosis. First, we include a dummy variable for whether the woman was offered ECHI (OFFER), and an interaction between ECHI and OFFER. ${ }^{13}$ We then focus on the interaction between ECHI and OFFER, conditioning on women being offered ECHI, on the presumption that those who took up the ECHI offer are dependent on their own work for insurance, whereas those who did not take it up are not. The idea is that women who were offered ECHI but did not accept it should have jobs with similar unobserved characteristics to those jobs held by women with ECHI, so that the difference among those offered ECHI - between those who take up the offer and those who do not provides a comparison among more homogeneous women than we get from the simple comparison

\footnotetext{
${ }^{13}$ Notice that because everyone who holds ECHI must have been offered ECHI, the interaction of ECHI and OFFER is the same variable as ECHI. In the context of this alternative regression we refer to this variable as OFFER $\times$ ECHI to make clear the dependence of ECHI on OFFER.
} 
between women with ECHI and without ECHI. ${ }^{14}$ The inclusion of the OFFER variable can be interpreted as adding a control for employer and job characteristics; any remaining differences between women who declined an offer of ECHI and those who accepted come from individuallevel differences, such as career orientation, insurance generosity relative to a spouse's policy, and degree of dependence on a spouse.

Second, to try to obtain a better comparison that holds constant individual-level differences, we estimate our specifications retaining the ECHI indicator, and adding an interaction term between ECHI and an indicator for whether or not the woman's spouse is insured through his own employer provided policy. We define a dummy variable NOSECHI equal to one when the spouse does not have this coverage. ${ }^{15}$ In this case, the ECHI versus nonECHI difference captures unobservables associated with ECHI, and instead we focus on the difference - among women with ECHI - between women who can switch to an insured spouse's policy (assuming his insurance offers coverage for his wife) and women who cannot, as the former group is less dependent on their own employment for health insurance. That is, we focus just on those women with ECHI, distinguishing between those who depend on their own employment for insurance $(\mathrm{NOSECHI}=1)$ and those who do not $(\mathrm{NOSECHI}=0)$. The prediction is that the coefficient of the ECHI $\times$ NOSECHI interaction should be positive, indicating that those with ECHI but without an option for coverage through their spouse are more likely to remain employed or to work longer hours after diagnosis. ${ }^{16}$

\footnotetext{
${ }^{14}$ This has some parallels to Gilleskie and Lutz (2002).

${ }^{15}$ There is not a NOSECHI main effect because the women in the sample either have ECHI or insurance through their spouse, so knowing the value of ECHI we know the value of NOSECHI.

${ }^{16}$ This parallels Madrian (1994). Note that because of HIPAA, these women could switch to their husband's policy despite the pre-existing condition. Among men that were offered insurance through their employer, $97 \%$ of the wives surveyed reported that they would be covered by their husband's policy.

It might seem more straightforward to include an interaction between ECHI and a dummy variable indicating spousal coverage (labeled SECHI - the opposite of NOSECHI). In that case, though, we would be testing for a negative effect. We find it simpler to use specifications that uniformly predict a positive coefficient on the variable indicating that a woman is reliant on her own employment for insurance.
} 
Finally, we estimate a similar specification, again effectively conditioning on ECHI but using information on whether the spouse is offered insurance (NOSOFFER), rather than whether the spouse has insurance (NOSECHI). The motivation is the same as for the previous specification; NOSECHI and NOSOFFER are two different ways of capturing whether a woman could potentially switch to a spouse's policy. The spouse offer comparison among those women with ECHI may be cleaner because whether or not the spouse takes up his ECHI may be more of a choice variable reflective of the wife's or the husband's individual or job characteristics.

\section{Results}

\section{Descriptive statistics}

Table 1 reports descriptive statistics for the sample. We start with a comparison between women with and without ECHI, in columns 1 and 2. Women with ECHI were more likely to be diagnosed at later stages and were more likely to have had chemotherapy by the second interview. Women with ECHI were more likely to be African American, responsible for a larger share of household income, and more likely to work for a large firm (100 or more employees) or to be employed by a government agency. They were also more likely to have jobs that required the analysis of data or other information, where they had to keep the pace set by others, and where they were required to sit for the majority of the day; but were less likely to require stooping, kneeling, or crouching.

At the two- and nine-month interviews, the percentages of women employed exceeded $80 \%$ and were comparable for women with and without ECHI. At all interviews, women with ECHI worked more weekly hours than women with insurance through a spouse. During the prediagnosis period, women with ECHI worked, on average, 44 hours per week whereas women without ECHI worked 37 hours per week. At the two-month interview, women with ECHI worked an average of 31 hours per week and women without ECHI worked 26 hours per week. 
And at the final interview, women with ECHI returned to nearly full-time work (on average, 38 hours per week), while women without ECHI worked about 30 hours per week. The differencein-difference in hours worked between women with ECHI and women with insurance through a spouse between baseline and the two-month and nine-month interviews were 1.8 and 1.7 hours, respectively, which are relatively small.

In columns 3 through 8 we present descriptive statistics for the other comparisons we use to estimate the effects of dependence on employment for insurance. These alternative comparisons use more homogeneous groups of women differentiated by this dependence, with the goal of reducing unobservable differences. The statistics in Table 1 speak to differences in observables, but if these differences are smaller it is likely that differences in unobservables follow suit.

Columns 3 and 4 focus on those offered ECHI, distinguishing between those who do and do not take it up. For this comparison, many of the differences that were statistically significant between columns 1 and 2 (for women with and without ECHI) remain statistically significant or large. This is not surprising, because this comparison still focuses on differences between women with and without ECHI, but in more similar jobs where insurance is offered. We might expect job characteristics to be more similar, but not necessarily individual characteristics. That appears to be the case. For example, the firm size distribution is more similar, as are the self-employment rates and job requirements, but the education distribution is more different.

The other two alternative comparisons, in columns 5 through 8 , would be expected to yield groups more similar on both job and individual characteristics, and that is true to some extent. For example, the racial distributions are no longer significantly different, nor are the firm size categories in columns 7 and 8 . Moreover, for the comparisons in columns 5 through 8 the differences in baseline hours worked are much more similar. Overall, the comparisons in the last 
two columns ("Alternative 3") appear most similar, and the comparisons in the last four columns are more similar than the others, suggesting that these alternative comparisons may give us the most reliable estimates of how dependence on one's job for health insurance affects the labor supply response to a health shock.

\section{Probability of employment}

Table 2 reports estimates of our models explaining the probability of being employed at the two- and nine-month interviews. In all estimations, the coefficient for ECHI is positive, consistent with women with ECHI being more likely to remain employed, but is statistically significant only in one estimation (column 3), where the estimate implies that women with ECHI were 5.29 percentage points more likely to be employed than women with health insurance through a spouse at the nine-month interview. This specification most closely replicates estimations from Bradley et al. (2006). ${ }^{17}$ In the expanded specification that includes controls for job and treatment characteristics and share of household income (column 4), the ECHI coefficient falls slightly from 5.29 to 4.74 percentage points and is no longer statistically significant. $^{18}$

\section{Change in weekly hours worked}

Table 3 reports estimates for our models explaining the percent change in weekly hours worked from the baseline interview to the two- and nine-month interviews. In the conditional (on employment) estimations of the baseline models for both the two- and nine-month interviews, there is statistically significant evidence that women with ECHI reduced their weekly hours by less than women with health insurance through a spouse (columns 1 and 3), although the

\footnotetext{
${ }^{17}$ In Bradley et al. (2006), women with ECHI were 10 percentage points more likely to be employed at six months following diagnosis, but this estimate was not statistically significant. At 12 months following diagnosis, women with ECHI were 13 percentage points more likely to be employed than women without ECHI $(\mathrm{p}<.05)$.

${ }^{18} \mathrm{We}$ tested specifications in which we included interaction terms between cancer stage and ECHI. Coefficients on these estimates were not statistically significant (results not shown). The full estimates including the coefficients of all the control variables are available upon request.
} 
magnitudes are not large (about 5 percent). The coefficient estimates remain positive, but are smaller and statistically insignificant in the specifications when other controls are added. The unconditional estimations in columns 5 through 8 mirror these findings, although all of the coefficients become larger because they reflect the employment effects of ECHI as well as change in hours worked.

\section{Alternative Comparisons}

In Table 4, we provide what we regard as more compelling tests of the dependence of labor supply on the need to maintain health insurance, using the alternative comparisons discussed earlier. All models include the full set of controls (expanded models). The first set of regressions (Alternative 1) focuses on those offered ECHI, distinguishing between those who take up ECHI and those who do not. The interaction term OFFER $\times$ ECHI is positive in all cases except one, but is significant in only one case (for employment at the nine-month interview). The positive estimates are consistent with women who are more dependent on their employment for health insurance working relatively more hours following a breast cancer diagnosis.

The second specification (Alternative 2) focuses on those with ECHI, distinguishing between women whose husbands have employer-provided health insurance. In this specification, a positive coefficient on the ECHI $\times$ NOSECHI interaction implies that women with a health shock who are more dependent on their own employment for insurance maintain higher labor supply. The hours estimates are all positive, and in column 2 the estimated coefficient on this interaction - for the change in hours conditional on working at the two-month interview - is both positive and statistically significant, suggesting that conditional on being employed, women with ECHI but without the option to switch to a spouse's policy reduce their hours less than women with ECHI whose spouse also has ECHI to which they can likely switch. This evidence is consistent with the hypothesis that dependence on employment for one's health insurance mutes 
the labor supply response to breast cancer, although the evidence is not strong and emerges only for some analyses.

In the final set of estimations (Alternative 3), we focus on whether the spouse is offered ECHI rather than whether the spouse has ECHI. We suggested that, on a priori grounds, this comparison might be the most compelling because whether or not the spouse takes up his ECHI may be more of a choice variable; the descriptive statistics in Table 1 appear to back this up, as the women we compare in this specification are the most similar on observables. Indeed, the evidence in the last two rows of Table 4 provides the strongest evidence consistent with our hypothesis. For three of the specifications there is statistically significant evidence that women more dependent on their own job for health insurance have higher labor supply following a health shock. We find this evidence for hours at both the two- and nine-month interviews, with estimated magnitudes in the 5.5 to 7 percent range.

Perceptions of the need to work to keep health insurance

Thus far, we focused on observed labor supply responses to ECHI. Next, we report responses to questions that ask women directly if they are working to preserve health insurance coverage (Table 5). The responses to these questions provide insight into the perceived link between ECHI and labor supply, which can provide complementary evidence to what we learn from observed behavior. We present these responses for the same comparisons we used in the regression analysis of labor supply responses.

As shown in columns 1 and 2, overwhelmingly women with ECHI perceive that they are working to maintain health insurance relative to women without ECHI. For example, at the twomonth interview, nearly two-thirds of women (63\%) with ECHI report that they strongly agree or agree with a statement affirming that they are working to maintain health insurance, relative to a 
tiny percentage among those without ECHI. ${ }^{19}$ The numbers are virtually the same in columns 3 and 4.

Of potentially more interest are the comparisons based only on women with ECHI or offered ECHI, where we infer dependence on one's employment for health insurance based on what might be available through the spouse. In columns 7 and 8 , where the comparison is based on whether or not the spouse is offered employer-provided health insurance, among women with ECHI, at the two-month interview women whose spouses are not offered health insurance are about 15 percentage points more likely to report they are currently working to maintain insurance, a statistically significant difference.

When we look at responses about whether women would reduce hours worked if they could have the same insurance without additional cost, we find even more consistent evidence that the need to maintain health insurance constrains labor supply choices of women with breast cancer. For the more reliable and meaningful comparisons - in columns 5 through 8 - which focus on differences among women with ECHI or offered ECHI, there are significant differences at the nine-month interview, with about 13 to14 percentage points more women whose husbands do not have or are not offered ECHI indicating that are maintaining higher hours than they want to maintain their health insurance.

\section{Discussion}

The evidence supports the hypothesis that ECHI incentivizes women newly diagnosed with breast cancer to maintain higher labor supply than they would otherwise. The estimated difference in labor supply responses to the health shock is modest - about 5 to 7 percent - and the evidence is somewhat sensitive to the choice of comparison groups. However, the evidence is strongest statistically when we compare women who differ in their dependency on their jobs for

\footnotetext{
${ }^{19}$ The question is not well-posed for those without ECHI, but we report the responses for completeness.
} 
continued insurance, but are otherwise most similar in terms of personal and job characteristics, which in our view strengthens the conclusion. In particular, the strongest evidence emerges from comparing women with ECHI, but differentiated only by whether their spouses are offered employer-provided health insurance that would cover the woman if she lost coverage through her employer. In addition, the subjective responses of women diagnosed with breast cancer to questions about whether they are working more to maintain health insurance are consistent with the conclusions from observed behavior.

Our study advances what is known about the relationship between ECHI and labor supply, and has two advantages over prior studies. First, we collected data on a rich set of control variables, including disease and treatment characteristics, job characteristics, and respondent and spouse characteristics, which were used to help rule out competing explanations of the observed effects. Second, we improved upon prior assessments of ECHI's effect on labor supply (our own included) by using alternative, more homogeneous comparison groups that better identify the effects of dependence on one's job for health insurance. In general, these alternative comparisons led to stronger evidence that dependence on one's employment for health insurance moderates labor supply reductions in response to breast cancer.

Our estimates of the magnitude of the difference in labor supply response to breast cancer for women who depend on their own employment for health insurance are consistently positive across specifications, but modest empirically. This evidence can be viewed as consistent with the job lock literature that suggests only a modest positive relationship between employmentcontingent insurance and job lock. Of course it differs in weighing evidence on a different channel by which employer-provided health insurance may constrain worker's labor market decisions - which we might think of as "hours lock" that constrains labor supply, rather than job lock that constrains mobility. 
In addition to drawing inferences from observed labor supply behavior, we questioned the women in our sample - all of whom had a breast cancer diagnosis - about their motivation to continue employment. There is a strong perception among with women dependent on their own employment for health insurance that they are working - or are working more - in order to maintain health insurance, which may explain worries related to insurance expressed by participants in qualitative studies of cancer survivorship (Schwartz et al. 2009). Although few women stopped working during the study period, concerns regarding health insurance insecurity are probably well founded given the strong correlation between job loss and loss of health insurance coverage (Cawley et al. 2011).

There are limitations to the study as well. First, the study is confined to a single state, which may limit whether it can be generalized to other settings. To mitigate this possibility, we enrolled subjects from academic and private practices and from rural and urban settings. Nonetheless, an advantage of focusing on a single state is that women in the sample were most likely subject to similar economic conditions that may affect employment.

Second, we study a single disease where treatment is reasonably uniform across practices. Again, this limits generalizability, but it can avoid the effects being obscured by heterogeneity of disease and treatments. Nonetheless, it would be valuable to gain more knowledge about how health insurance that is tied to one's job influences labor supply responses to different types of health shocks, although collecting the requisite data, as in our study, is expensive.

Third, we study married women, so the findings may not generalize to single women (or men) who do not have the option to switch to a spouse's policy, nor to married men who are less likely to have the option to switch to a wife's policy. Prior work suggests that men will be more constrained by ECHI following the diagnosis of a serious illness because they are likely to have fewer options than women to switch to their spouse's employer-provided health insurance 
(Bradley et al., 2011).

Fourth, in spite of our attempts to enroll and study similar groups of women, in the absence of randomization of employees to equivalent ECHI policies and non-ECHI policies, dissimilarities between the treatment and control groups are inevitable. Dissimilarities can occur between study subjects, comparability of insurance policies, and jobs. We therefore cannot completely rule out bias from selection into different health insurance statuses. Absent an experimental design, we tried to overcome or assess this limitation by studying more similar groups of women. The overall consistency of our findings, and the fact that they are stronger when we use comparisons among more homogeneous groups of women who are still differentiated by how dependent they are on their own employment for health insurance, should bolster confidence in the findings.

The evidence that dependence on employment for health insurance creates an incentive to maintain higher labor supply when faced with a health shock, and that women strongly perceive this incentive, suggests that employer-provided health insurance may lead to anxiety or stress among people who experience a health shock and are dependent on employment for their health insurance. Moreover, the resulting constraint on reducing labor supply may influence treatment decisions and adherence behavior to avoid reducing labor supply as much. Future research will explore the effects on treatment, adherence, and health consequences of the dependence on employment for health insurance. From a public policy perspective, having better and cheaper options for health insurance outside of the employer may benefit some workers. At the same time, the relatively modest differences we find in labor supply responses to health shocks suggest that providing these alternatives outside the employer-based system are unlikely to trigger substantial reductions in labor supply. 


\section{References}

Bradley CJ, Neumark D, Luo Z, Bednarek H. Employment-based health insurance, illness, and labor supply of women: evidence from married women with breast cancer. Health Economics 2006;16(7):719-734.

Bradley CJ, Neumark D, Luo Z, Schenk M. Employment and cancer: findings from a longitudinal study of breast and prostate cancer survivors. Cancer Investigation 2007;25(1):4754.

Bradley CJ, Neumark D, Motika M. The effects of health shocks on employment and health insurance: the role of employer-provided health insurance. National Bureau of Economic Research Working Paper 17223. 2011. http://www.nber.org/papers/w17223. Accessed November 22, 2011.

Cawley J, Moriya AS, Simon KI. The impact of the macroeconomy on health insurance coverage: evidence from the great recession. National Bureau of Economic Research Working Paper 17600. 2011. http://www.nber.org/papers/w17600.pdf. Accessed April 26, 2012.

Cooper PF, Monheit AC. Does employment-related health insurance inhibit job mobility? Inquiry 1993;30(4):400-416.

Gabel JR, McDevitt R, Lore R, Pickreign J, Whitmore H, Ding T. Trends in underinsurance and the affordability of employer coverage, 2004-2007. Health Affairs 2009;28(4):w595-606.

Gilleskie DB, Lutz BF. The impact of employer-provided health insurance on dynamic employment transitions. The Journal of Human Resources 2002;37(1):129-162.

Hassett MJ, O'Malley AJ, Keating NL. Factors influencing changes in employment among women with newly diagnosed breast cancer. Cancer 2009;115(12):2775-2782.

Henry J. Kaiser Family Foundation. Focus on health reform: summary of coverage provisions in the Patient Protection and Affordable Care Act. 2011. http://www.kff.org/ healthreform/upload/8023-R.pdf. Accessed January 26, 2012.

Johnsson A, Fornander T, Rutgvist LE, Olsson M. Work status and life changes in the first year after breast cancer diagnosis. Work 2011;38(4):337-346.

Kapur K. The impact of health on job mobility: a measure of job lock. Industrial and Labor Relations Review 1998;51(2):282-298.

Madrian B. Employment-based health insurance and job mobility: Is there evidence of job lock? The Quarterly Journal of Economics 1994; 109(1):27-54.

Mujahid MS, Janz NK, Hawley ST, Griggs JJ, Hamilton AS, Graff J, Katz SJ. Racial/ethnic differences in job loss for women with breast cancer. Journal of Cancer Survivorship 2011;5(1):102-111. 
National Cancer Institute (a). Estimated U.S. cancer prevalence. 2011. http://cancercontrol. cancer.gov/ocs/prevalence/prevalence.html\#allsites. Accessed November 10, 2011.

National Cancer Institute (b). SEER Stat Fact Sheets: Breast. 2011. http://seer.cancer.gov/statfacts/html/breast.html\#incidence-mortality. Accessed November 22, 2011.

Schwartz K, Claxton G, Martin K, Schmidt C. Spending to survive: cancer patients confront holes in the health insurance system. 2009. http://www.kff.org/insurance/upload/7851.pdf. Accessed April 26, 2012.

Stephan P. Breast cancer treatment and recovery times: treatment schedule and time management during breast cancer. 2010. http://breastcancer.about.com/od/whattoexpect/a/Breast-CancerTreatment-Recovery-Times.htm. Accessed November 10, 2011.

Tunceli K, Short PF, Moran JR, Tunceli O. Cancer survivorship, health insurance, and employment transitions among older workers. Inquiry 2009;46(1):17-32.

United States Department of Labor Employee Benefits Security Administration. COBRA continuation coverage assistance under ARRA. 2011. http://www.dol.gov/ebsa/COBRA.html. Accessed January 26, 2012.

United States Department of Labor Wage and Hour Division. Family and Medical Leave Act. 2012. http://www.dol.gov/whd/fmla. Accessed April 26, 2012. 
Figure 1. Subject identification, enrollment, and retention

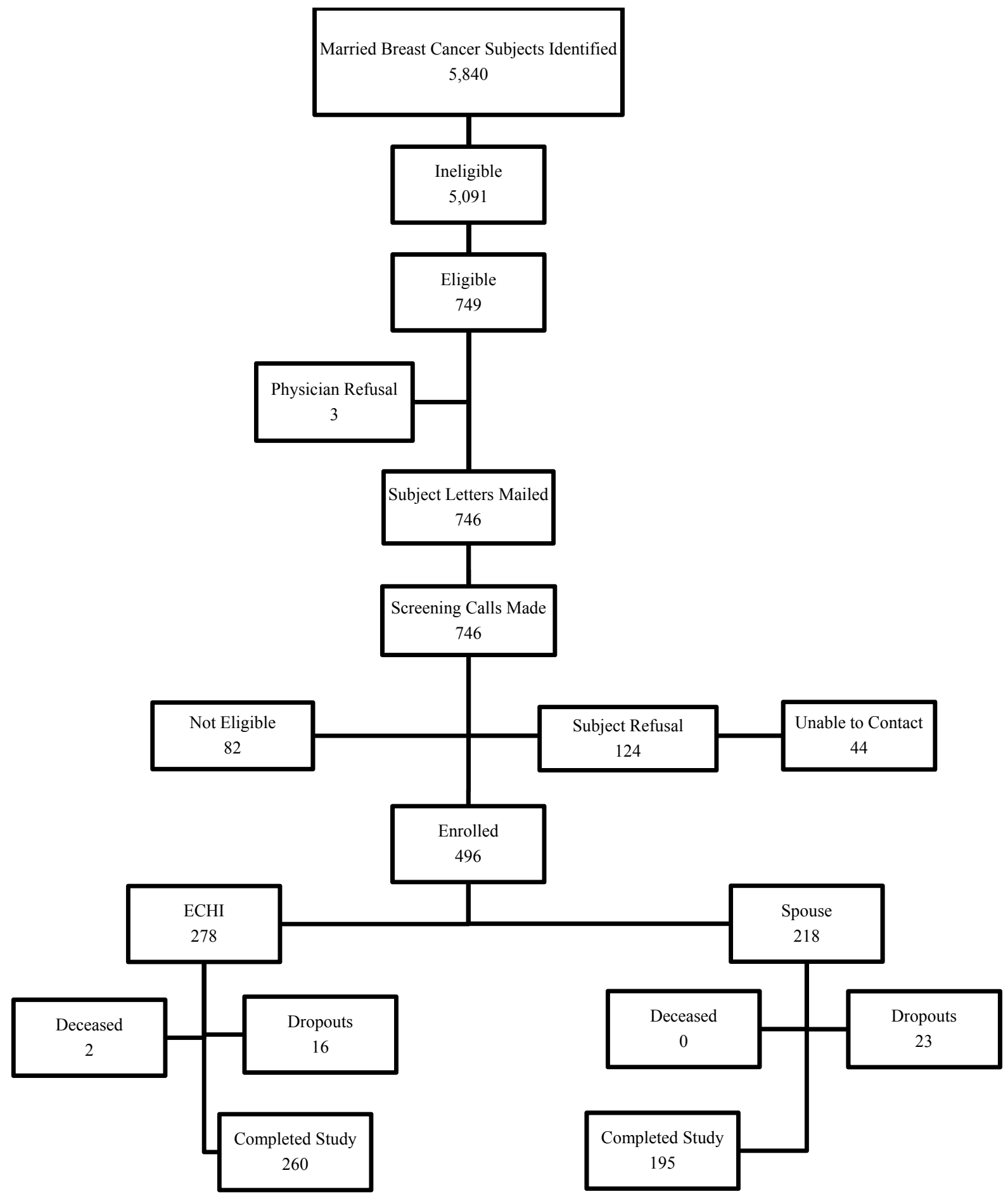


Table 1. Descriptive statistics at baseline interview

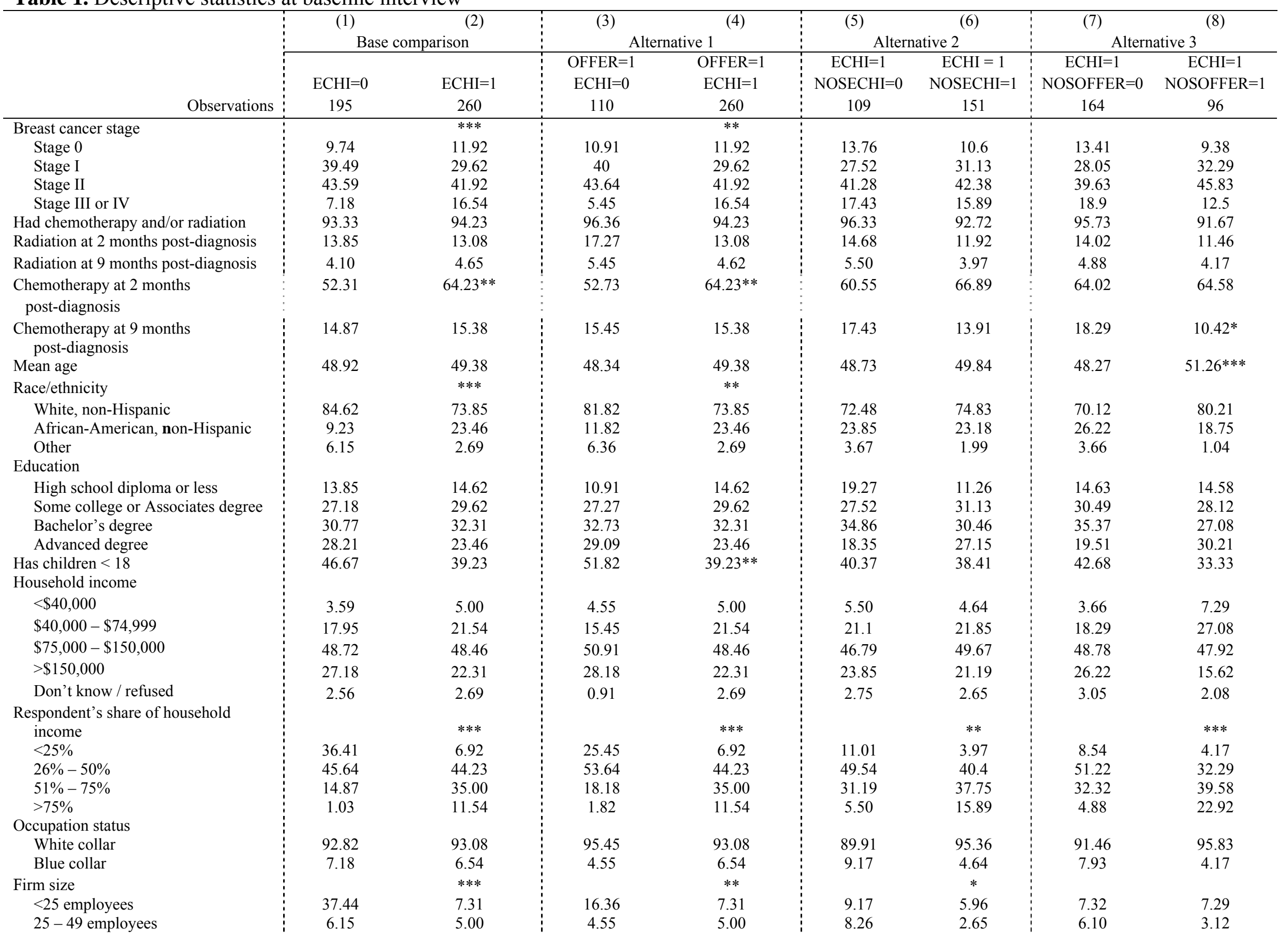




\begin{tabular}{|c|c|c|c|c|c|c|c|c|}
\hline \multirow[b]{5}{*}{ Observations } & (1) & $(2)$ & (3) & (4) & $(5)$ & (6) & (7) & (8) \\
\hline & \multicolumn{2}{|c|}{ Base comparison } & \multicolumn{2}{|c|}{ Alternative 1} & \multicolumn{2}{|c|}{ Alternative 2} & \multicolumn{2}{|c|}{ Alternative 3} \\
\hline & & & OFFER $=1$ & OFFER $=1$ & $\mathrm{ECHI}=1$ & $\mathrm{ECHI}=1$ & $\mathrm{ECHI}=1$ & $\mathrm{ECHI}=1$ \\
\hline & $\mathrm{ECHI}=0$ & $\mathrm{ECHI}=1$ & $\mathrm{ECHI}=0$ & $\mathrm{ECHI}=1$ & NOSECHI $=0$ & NOSECHI $=1$ & NOSOFFER $=0$ & NOSOFFER $=1$ \\
\hline & 195 & 260 & 110 & 260 & 109 & 151 & 164 & 96 \\
\hline $50-99$ employees & 6.67 & 5.00 & 10.00 & 5.00 & 2.75 & 6.62 & 3.05 & 8.33 \\
\hline $100+$ employees & 49.74 & 82.31 & 69.09 & 82.31 & 78.9 & 84.77 & 82.93 & 81.25 \\
\hline Firm type & & $* * *$ & & & & & & \\
\hline Government & 21.03 & 39.23 & 30.00 & 39.23 & 35.78 & 41.72 & 37.80 & 41.67 \\
\hline Private, for-profit & 53.85 & 48.08 & 53.64 & 48.08 & 51.38 & 45.70 & 49.39 & 45.83 \\
\hline Non-profit & 13.33 & 10.00 & 13.64 & 10.00 & 8.26 & 11.26 & 9.76 & 10.42 \\
\hline Self-employed & 11.79 & 2.31 & 2.73 & 2.31 & 3.67 & 1.32 & 2.44 & 2.08 \\
\hline \multicolumn{9}{|l|}{$\begin{array}{l}\text { Job requires all/almost all the time or } \\
\text { most of the time }\end{array}$} \\
\hline Lots of physical effort & 28.72 & 25.38 & 26.36 & 25.38 & 23.85 & 26.49 & 25.00 & 26.04 \\
\hline Intense concentration or attention & 80.00 & 82.69 & 78.18 & 82.69 & 77.98 & $86.09^{*}$ & 79.88 & 87.50 \\
\hline Lifting heavy loads & 7.69 & 8.85 & 6.36 & 8.85 & 8.26 & 9.27 & 9.15 & 8.33 \\
\hline Stooping, kneeling, or crouching & 23.59 & $17.31 *$ & 21.82 & 17.31 & 11.01 & $21.85 * *$ & 14.63 & 21.88 \\
\hline Analysis of data or information & 63.08 & $72.69 * *$ & 68.18 & 72.69 & 71.56 & 73.51 & 72.56 & 72.92 \\
\hline Learning new things & 54.36 & 58.46 & 51.82 & 58.46 & 58.72 & 58.28 & 57.32 & 60.42 \\
\hline Good eyesight & 88.72 & 88.85 & 88.18 & 88.85 & 88.07 & 89.40 & 86.59 & 92.71 \\
\hline Keeping up with pace set by others & 45.13 & $36.92 * *$ & 47.27 & $36.92 *$ & 43.12 & $32.45^{*}$ & 39.63 & 32.29 \\
\hline Number of hours sitting per day & & $* *$ & & & & & & \\
\hline$<2.5$ hours & 30.77 & 23.08 & 29.09 & 23.08 & 24.77 & 21.85 & 22.56 & 23.96 \\
\hline 2.5 to 4.5 hours & 31.28 & 25.00 & 25.45 & 25.00 & 23.85 & 25.83 & 25.61 & 23.96 \\
\hline 5 to 7 & 26.15 & 31.92 & 29.09 & 31.92 & 30.28 & 33.11 & 29.27 & 36.46 \\
\hline$>7$ hours & 11.79 & 20.00 & 16.36 & 20.00 & 21.10 & 19.21 & 22.56 & 15.62 \\
\hline Employed 2 months & 83.08 & 83.08 & 81.82 & 83.08 & 85.32 & 81.46 & 84.76 & 80.21 \\
\hline Employed 9 months & 87.69 & 91.92 & 86.36 & $91.92 *$ & 90.83 & 92.72 & 91.46 & 92.71 \\
\hline $\begin{array}{l}\text { Mean weekly hours worked (SD), } \\
\text { baseline }\end{array}$ & $37.26(13.34)$ & $43.97(8.30)^{* * *}$ & $40.59(10.40)$ & $43.97(8.30)^{* * *}$ & $43.36(7.58)$ & $44.42(8.78)$ & $43.65(7.97)$ & $44.52(8.85)$ \\
\hline Mean weekly hours worked (SD), & & & & & & & & \\
\hline 2 months & $25.96(16.68)$ & $30.89(16.92)^{* * *}$ & $28.57(16.90)$ & $30.89(16.92)$ & $30.42(15.95)$ & $31.23(17.62)$ & $31.12(16.39)$ & $30.50(17.85)$ \\
\hline $\begin{array}{l}\text { Mean weekly hours worked (SD), } \\
9 \text { months }\end{array}$ & $29.79(16.35)$ & $38.11(14.27)^{* * *}$ & $32.63(15.86)$ & $38.11(14.27)^{* * *}$ & $36.74(14.33)$ & $39.10(14.19)$ & $37.22(14.11)$ & $39.64(14.48)$ \\
\hline
\end{tabular}

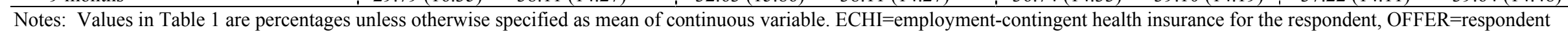

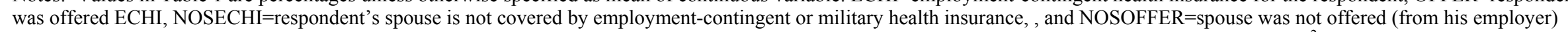

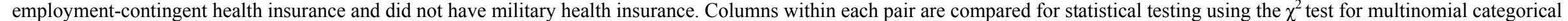

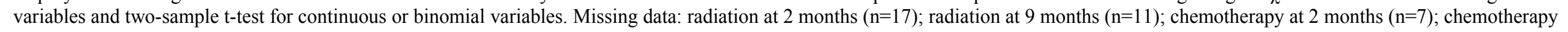

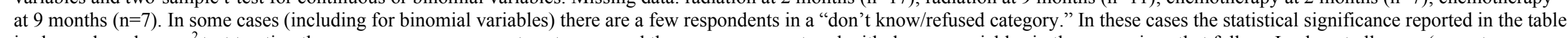

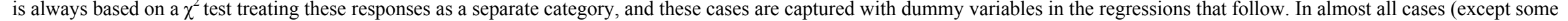

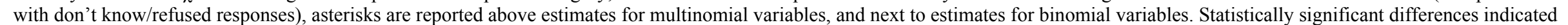
as: ${ }^{*} \mathrm{p}<.10, * * \mathrm{p}<.05, * * * \mathrm{p}<.01$. 
Table 2. Linear probability models of employment at two-month and nine-month interviews

\begin{tabular}{|c|c|c|c|c|}
\hline & \multirow{2}{*}{\multicolumn{2}{|c|}{$\begin{array}{l}\text { (1) } \\
\text { Two-month interview }\end{array}$}} & \multirow{2}{*}{\multicolumn{2}{|c|}{$\begin{array}{l}(3) \\
\text { Nine-month interview }\end{array}$}} \\
\hline & & & & \\
\hline & Baseline model & Expanded model & Baseline model & Expanded model \\
\hline ECHI & $\begin{array}{c}0.0129 \\
(0.0393)\end{array}$ & $\begin{array}{c}0.0150 \\
(0.0441)\end{array}$ & $\begin{array}{l}0.0529^{*} \\
(0.0302)\end{array}$ & $\begin{array}{c}0.0474 \\
(0.0326)\end{array}$ \\
\hline \multicolumn{5}{|l|}{ Breast Cancer Stage } \\
\hline Stage 0 & $\begin{array}{c}0.0300 \\
(0.0418)\end{array}$ & $\begin{array}{c}0.0317 \\
(0.0476)\end{array}$ & $\begin{array}{l}-0.0817 \\
(0.0573)\end{array}$ & $\begin{array}{l}-0.0492 \\
(0.0663)\end{array}$ \\
\hline Stage II & $\begin{array}{c}-0.140 * * * \\
(0.0332)\end{array}$ & $\begin{array}{l}-0.103 * * \\
(0.0425)\end{array}$ & $\begin{array}{c}-0.0812 * * * \\
(0.0302)\end{array}$ & $\begin{array}{l}-0.0594^{*} \\
(0.0299)\end{array}$ \\
\hline Stage III or IV & $\begin{array}{l}-0.132 * \\
(0.0665)\end{array}$ & $\begin{array}{l}-0.123^{*} \\
(0.0724)\end{array}$ & $\begin{array}{c}-0.101 \\
(0.0640)\end{array}$ & $\begin{array}{l}-0.0853 \\
(0.0545)\end{array}$ \\
\hline $\begin{array}{l}\text { Treatment indicators, job } \\
\text { characteristics, and } \\
\text { household income share } \\
\text { included }\end{array}$ & No & Yes & No & Yes \\
\hline \multicolumn{5}{|c|}{$\begin{array}{l}\text { Notes: There are } 455 \text { observations. Standard errors in parentheses: }{ }^{*} p<.1,{ }^{* *} p<.05,{ }^{* * *} p<.01 \text { (two-tailed tests). } \\
\text { ECHI=employment-contingent health insurance. OLS regressions with robust standard errors clustered by physician. Stage I is } \\
\text { the omitted cancer stage. Controls in baseline model include age in years, indicator of chemotherapy or radiation observed at } \\
\text { any point, pre-diagnosis weekly hours worked, and sets of dummy indicators for race, education level, having children under } \\
\text { age } 18 \text {, household income, whether the respondent's job is a blue collar job, and year of interview (2007 to } 2011 \text { ). Treatment } \\
\text { indicators designate that chemotherapy and/or radiation was being received at the time of the two-month or nine-month } \\
\text { interview. Job characteristics include sets of dummies for firm size }(<25,25 \text { to } 49,50 \text { to } 99,100 \text { or more employees) and firm } \\
\text { type, categories for number of hours spent sitting daily, and other job requirements: physical effort, intense concentration, } \\
\text { lifting, stooping/kneeling/crouching, data analysis, keep pace set by others, learning new things, and good eyesight. Household } \\
\text { income share indicates the respondent's share as a percentage of her household income ( }(\leq 25 \%, 26 \% \text { to } 50 \%, 51 \% \text { to } 75 \% \text {, and } \\
>75 \%) \text {. }\end{array}$} \\
\hline
\end{tabular}


Table 3. Percentage change in hours worked, conditional and unconditional on working post-diagnosis

$\begin{array}{llllll}(1) & (2) & \text { (3) } & \text { (4) }\end{array}$

(7)

(8)

\begin{tabular}{|c|c|c|c|c|c|c|c|c|}
\hline & \multicolumn{4}{|c|}{ Conditional on working } & \multicolumn{4}{|c|}{ Not conditional on working } \\
\hline & \multirow{2}{*}{\multicolumn{2}{|c|}{$\frac{\mathrm{N}=378}{\text { Two-month interview }}$}} & \multirow{2}{*}{\multicolumn{2}{|c|}{$\frac{\mathrm{N}=410}{\text { Nine-month interview }}$}} & \multicolumn{4}{|c|}{$\mathrm{N}=455$} \\
\hline & & & & & \multicolumn{2}{|c|}{ Two-month interview } & \multicolumn{2}{|c|}{ Nine-month interview } \\
\hline & $\begin{array}{c}\text { Baseline } \\
\text { model }\end{array}$ & $\begin{array}{c}\text { Expanded } \\
\text { model }\end{array}$ & $\begin{array}{c}\text { Baseline } \\
\text { model }\end{array}$ & $\begin{array}{c}\text { Expanded } \\
\text { model }\end{array}$ & $\begin{array}{c}\text { Baseline } \\
\text { model }\end{array}$ & $\begin{array}{c}\text { Expanded } \\
\text { model }\end{array}$ & $\begin{array}{c}\text { Baseline } \\
\text { model }\end{array}$ & $\begin{array}{c}\text { Expanded } \\
\text { model }\end{array}$ \\
\hline ECHI & $\begin{array}{c}0.0479 * * \\
(0.0222)\end{array}$ & $\begin{array}{c}0.0286 \\
(0.0262)\end{array}$ & $\begin{array}{l}0.0584 * \\
(0.0326)\end{array}$ & $\begin{array}{c}0.0128 \\
(0.0300)\end{array}$ & $\begin{array}{l}0.0610^{*} \\
(0.0353)\end{array}$ & $\begin{array}{c}0.0435 \\
(0.0426)\end{array}$ & $\begin{array}{l}0.102 * * \\
(0.0389)\end{array}$ & $\begin{array}{c}0.0490 \\
(0.0380)\end{array}$ \\
\hline
\end{tabular}

Breast Cancer Stage

\begin{tabular}{|c|c|c|c|c|c|c|c|c|}
\hline Stage 0 & $\begin{array}{l}0.0492 * \\
(0.0259)\end{array}$ & $\begin{array}{l}0.00233 \\
(0.0332)\end{array}$ & $\begin{array}{c}0.0461 \\
(0.0282)\end{array}$ & $\begin{array}{c}0.0314 \\
(0.0275)\end{array}$ & $\begin{array}{c}0.0648 \\
(0.0487)\end{array}$ & $\begin{array}{c}0.0216 \\
(0.0531)\end{array}$ & $\begin{array}{l}-0.0357 \\
(0.0658)\end{array}$ & $\begin{array}{c}-0.00800 \\
(0.0691)\end{array}$ \\
\hline Stage II & $\begin{array}{c}-0.0713^{* *} \\
(0.0301)\end{array}$ & $\begin{array}{l}-0.0548 \\
(0.0340)\end{array}$ & $\begin{array}{c}0.0249 \\
(0.0343)\end{array}$ & $\begin{array}{c}0.0204 \\
(0.0345)\end{array}$ & $\begin{array}{c}-0.184^{* * *} \\
(0.0354)\end{array}$ & $\begin{array}{c}-0.138 * * * \\
(0.0427)\end{array}$ & $\begin{array}{l}-0.0551 \\
(0.0361)\end{array}$ & $\begin{array}{l}-0.0388 \\
(0.0361)\end{array}$ \\
\hline Stage III or IV & $\begin{array}{c}-0.103 * * \\
(0.0462)\end{array}$ & $\begin{array}{l}-0.0725^{*} \\
(0.0432)\end{array}$ & $\begin{array}{l}0.00862 \\
(0.0372)\end{array}$ & $\begin{array}{l}-0.00627 \\
(0.0278)\end{array}$ & $\begin{array}{c}-0.203 * * * \\
(0.0642)\end{array}$ & $\begin{array}{c}-0.172 * * * \\
(0.0646)\end{array}$ & $\begin{array}{c}-0.102 \\
(0.0693)\end{array}$ & $\begin{array}{c}-0.110 * \\
(0.0619)\end{array}$ \\
\hline
\end{tabular}

Treatment indicators, job

No

Yes

No

Yes

No

Yes

No

Yes

household income share

included

Notes: Standard errors in parentheses: ${ }^{*} p<.1,{ }^{* *} p<.05,{ }^{* * *} p<.01$ (two-tailed tests). ECHI=employment-contingent health insurance. All regressions estimated using OLS with robust standard errors clustered by physician. Stage I is the omitted cancer stage. Controls are the same as noted in Table 2. 
Table 4. Labor supply outcomes, alternative specifications of expanded model

\begin{tabular}{|c|c|c|c|c|c|c|}
\hline & (1) & $(2)$ & (3) & (4) & $(5)$ & (6) \\
\hline & \multicolumn{3}{|c|}{ Two-month interview } & \multicolumn{3}{|c|}{ Nine-month interview } \\
\hline & Employment & $\begin{array}{l}\text { Percent change in } \\
\text { hours, conditional } \\
\text { on working }\end{array}$ & $\begin{array}{l}\text { Percent change } \\
\text { in hours, } \\
\text { unconditional }\end{array}$ & Employment & $\begin{array}{l}\text { Percent change in } \\
\text { hours, conditional } \\
\text { on working }\end{array}$ & $\begin{array}{l}\text { Percent change } \\
\text { in hours, } \\
\text { unconditional }\end{array}$ \\
\hline \multicolumn{7}{|l|}{ Alternative 1} \\
\hline OFFER & $\begin{array}{l}-0.0711 \\
(0.0771)\end{array}$ & $\begin{array}{c}0.0527 \\
(0.0539)\end{array}$ & $\begin{array}{l}0.00153 \\
(0.0850)\end{array}$ & $\begin{array}{l}-0.0660 \\
(0.0574)\end{array}$ & $\begin{array}{l}0.0832 \\
(0.104)\end{array}$ & $\begin{array}{l}0.0244 \\
(0.103)\end{array}$ \\
\hline OFFER $\times$ ECHI & $\begin{array}{c}0.0352 \\
(0.0527)\end{array}$ & $\begin{array}{c}0.0135 \\
(0.0250)\end{array}$ & $\begin{array}{c}0.0443 \\
(0.0490)\end{array}$ & $\begin{array}{l}0.0650 * \\
(0.0361)\end{array}$ & $\begin{array}{l}-0.0102 \\
(0.0363)\end{array}$ & $\begin{array}{c}0.0412 \\
(0.0432)\end{array}$ \\
\hline \multicolumn{7}{|l|}{ Alternative 2} \\
\hline $\mathrm{ECHI}$ & $\begin{array}{c}0.0393 \\
(0.0505)\end{array}$ & $\begin{array}{l}-0.0134 \\
(0.0324)\end{array}$ & $\begin{array}{c}0.0276 \\
(0.0528)\end{array}$ & $\begin{array}{c}0.0499 \\
(0.0411)\end{array}$ & $\begin{array}{l}-0.00501 \\
(0.0307)\end{array}$ & $\begin{array}{c}0.0284 \\
(0.0444)\end{array}$ \\
\hline $\mathrm{ECHI} \times \mathrm{NOSECHI}$ & $\begin{array}{l}-0.0452 \\
(0.0424)\end{array}$ & $\begin{array}{c}0.0813 * * \\
(0.0319)\end{array}$ & $\begin{array}{c}0.0296 \\
(0.0457)\end{array}$ & $\begin{array}{l}-0.00472 \\
(0.0318)\end{array}$ & $\begin{array}{c}0.0336 \\
(0.0299)\end{array}$ & $\begin{array}{c}0.0388 \\
(0.0418)\end{array}$ \\
\hline $\begin{array}{l}\text { Alternative } 3 \\
\text { ECHI }\end{array}$ & $\begin{array}{c}0.0294 \\
(0.0425)\end{array}$ & $\begin{array}{l}0.00992 \\
(0.0267)\end{array}$ & $\begin{array}{c}0.0401 \\
(0.0413)\end{array}$ & $\begin{array}{c}0.0446 \\
(0.0349)\end{array}$ & $\begin{array}{l}-0.00547 \\
(0.0299)\end{array}$ & $\begin{array}{c}0.0259 \\
(0.0391)\end{array}$ \\
\hline $\mathrm{ECHI} \times$ NOSOFFER & $\begin{array}{l}-0.0440 \\
(0.0463)\end{array}$ & $\begin{array}{l}0.0590 * \\
(0.0299)\end{array}$ & $\begin{array}{c}0.0103 \\
(0.0415)\end{array}$ & $\begin{array}{l}0.00832 \\
(0.0335)\end{array}$ & $\begin{array}{c}0.0551 * * \\
(0.0268)\end{array}$ & $\begin{array}{l}0.0704^{*} \\
(0.0360)\end{array}$ \\
\hline
\end{tabular}

Notes: Standard errors in parentheses: ${ }^{*} p<.1,{ }^{* *} p<.05,{ }^{* * *} p<.01$ (two-tailed tests). ECHI=employment-contingent health insurance for the respondent, OFFER=respondent was offered ECHI, NOSECHI=respondent's spouse is not covered by employment-contingent or military health insurance, and NOSOFFER=spouse was not offered (from his employer) employment-contingent health insurance and did not have military health insurance. All regressions run using OLS with standard errors clustered by physician, and all include the same set of control variables as what was included in the "expanded" models in Tables 2 and 3. Sample sizes are reduced by two non-ECHI respondents in regressions that include the variable OFFER because those respondents were not asked if they were offered insurance from their employer due to interviewer error. 
Table 5. Reasons for continued employment and hours worked, $\%$

\begin{tabular}{|c|c|c|c|c|c|c|c|c|}
\hline \multirow{3}{*}{ Survey question } & \multirow{2}{*}{\multicolumn{2}{|c|}{$\begin{array}{l}(1) \\
\text { Base specification }\end{array}$}} & \multirow{2}{*}{\multicolumn{2}{|c|}{$\begin{array}{l}\text { (3) } \\
\text { Alternative } 1\end{array}$}} & \multirow{2}{*}{\multicolumn{2}{|c|}{ Alternative $2^{(6)}$}} & \multirow{2}{*}{\multicolumn{2}{|c|}{ Alternative $3^{(8)}$}} \\
\hline & & & & & & & & \\
\hline & \multirow[t]{2}{*}{$\mathrm{ECHI}=0$} & \multirow[t]{2}{*}{$\mathrm{ECHI}=1$} & $\begin{array}{c}\mathrm{OFFER}=1 \\
\mathrm{ECHI}=0\end{array}$ & $\begin{array}{l}\mathrm{OFFER}=1 \\
\mathrm{ECHI}=1\end{array}$ & $\begin{array}{c}\mathrm{ECHI}=1 \\
\mathrm{NOSECHI}=0\end{array}$ & $\begin{array}{c}\mathrm{ECHI}=1 \\
\mathrm{NOSECHI}=1\end{array}$ & $\begin{array}{c}\mathrm{ECHI}=1 \\
\text { NOSOFFER }=0\end{array}$ & $\begin{array}{c}\text { ECHI }=1 \\
\text { NOSOFFER }=1\end{array}$ \\
\hline \multicolumn{7}{|l|}{ Two-month interview } & & \\
\hline $\begin{array}{l}\text { Are you currently working to maintain } \\
\text { health insurance benefits? }\end{array}$ & $\begin{array}{c}3.70 \\
(\mathrm{~N}=162)\end{array}$ & $\begin{array}{l}62.96 * * * \\
(\mathrm{~N}=216)\end{array}$ & $\begin{array}{c}3.33 \\
(\mathrm{~N}=90)\end{array}$ & $\begin{array}{l}62.96 * * * \\
(\mathrm{~N}=216)\end{array}$ & $\begin{array}{c}58.06 \\
(\mathrm{~N}=93)\end{array}$ & $\begin{array}{c}66.67 \\
(\mathrm{~N}=123)\end{array}$ & $\begin{array}{c}57.55 \\
(\mathrm{~N}=139)\end{array}$ & $\begin{array}{l}72.73 * * \\
(\mathrm{~N}=77)\end{array}$ \\
\hline $\begin{array}{l}\text { If you could have the same health } \\
\text { insurance without additional cost to } \\
\text { you, would you reduce the number of } \\
\text { hours you work each week? }\end{array}$ & $\begin{array}{c}29.33 \\
(\mathrm{~N}=150)\end{array}$ & $\begin{array}{l}48.15 * * * \\
(\mathrm{~N}=216)\end{array}$ & $\begin{array}{c}27.91 \\
(\mathrm{~N}=86)\end{array}$ & $\begin{array}{l}48.15 * * * \\
(\mathrm{~N}=216)\end{array}$ & $\begin{array}{c}48.39 \\
(\mathrm{~N}=93)\end{array}$ & $\begin{array}{c}47.97 \\
(\mathrm{~N}=123)\end{array}$ & $\begin{array}{c}48.92 \\
(\mathrm{~N}=139)\end{array}$ & $\begin{array}{c}46.75 \\
(\mathrm{~N}=77)\end{array}$ \\
\hline \multicolumn{9}{|l|}{ Nine-month interview } \\
\hline $\begin{array}{l}\text { Are you currently working to maintain } \\
\text { health insurance benefits? }\end{array}$ & $\begin{array}{c}7.02 \\
(\mathrm{~N}=171)\end{array}$ & $\begin{array}{l}66.95 * * * \\
(\mathrm{~N}=239)\end{array}$ & $\begin{array}{c}11.58 \\
(\mathrm{~N}=95)\end{array}$ & $\begin{array}{l}66.95 * * * \\
(\mathrm{~N}=239)\end{array}$ & $\begin{array}{c}66.67 \\
(\mathrm{~N}=99)\end{array}$ & $\begin{array}{c}67.14 \\
(\mathrm{~N}=140)\end{array}$ & $\begin{array}{c}64.00 \\
(\mathrm{~N}=150)\end{array}$ & $\begin{array}{c}71.91 \\
(\mathrm{~N}=89)\end{array}$ \\
\hline $\begin{array}{l}\text { If you could have the same health } \\
\text { insurance without additional cost to } \\
\text { you, would you reduce the number of } \\
\text { hours you work each week? }\end{array}$ & $\begin{array}{c}27.04 \\
(\mathrm{~N}=159)\end{array}$ & $\begin{array}{l}49.79 * * * \\
(\mathrm{~N}=239)\end{array}$ & $\begin{array}{c}30.00 \\
(\mathrm{~N}=90)\end{array}$ & $\begin{array}{c}49.79 * * * \\
(\mathrm{~N}=239)\end{array}$ & $\begin{array}{c}41.41 \\
(\mathrm{~N}=99)\end{array}$ & $\begin{array}{l}55.71 * * \\
(\mathrm{~N}=140)\end{array}$ & $\begin{array}{c}45.33 \\
(\mathrm{~N}=150)\end{array}$ & $\begin{array}{l}57.30 * \\
(\mathrm{~N}=89)\end{array}$ \\
\hline
\end{tabular}

